\title{
Hydroarylation of $N$-Allenyl Derivatives Catalyzed by Copper
}

\author{
Racha Abed Ali Abdine, ${ }^{\#, a}$ Lucas Pagès, ${ }^{\# \text { a }}$ Marc Taillefer, ${ }^{\mathrm{a}, *}$ and Florian Monnier ${ }^{\mathrm{a}, \mathrm{b}, *}$
}

a Ecole Nationale Supérieure de Chimie de Montpellier, Institut Charles Gerhardt Montpellier UMR 5253, Univ. Montpellier, CNRS, ENSCM, 8 rue de l'Ecole Normale, Montpellier 34296 Cedex 5, France.

E-mail : marc.taillefer@enscm.fr; florian.monnier@enscm.fr

b Institut Universitaire de France, IUF, 1 rue Descartes, Paris 75231 Cedex 5, France.

\# These two authors contributed equally to this work.

\begin{abstract}
A additive-free copper catalytic system was used to perform the addition of (hetero)aryl nucleophiles to $\mathrm{N}$-allenyl derivatives. This intermolecular $\mathrm{C}-\mathrm{C}$ bond formation occurs with both complete regio- and stereoselectivity to afford the linear $(E)$ allylic product with moderate to excellent yields. This atom economical method is the first example of hydroarylation of allenes catalyzed by copper.
\end{abstract}

Keywords: allenes; copper; hydroarylation; allylic compounds, arenes, homogeneous catalysis

Allylic or vinylic molecules are highly valuable intermediates ${ }^{[1]}$ which are easy-to-prepare through transition metal-catalyzed hydrofunctionalization of monosubstituted allenes. ${ }^{[2-4]}$ This atom economical strategy usually occurs without any prefunctionalization and with very high chemo-, regioand stereospecificity. Hydrofunctionalization of allenes mainly allowed the selective formation of $\mathrm{C}-\mathrm{N}$, $\mathrm{C}-\mathrm{O}$ and $\mathrm{C}-\mathrm{C}$ bond. ${ }^{[2,3,5-8]}$ The latter being performed through the addition of pronucleophiles such as malonates, ${ }^{[9-12]}$ nitriles, ${ }^{[13-16]}$ alkynes, ${ }^{[17-19]}$ alkenes ${ }^{[20-}$ 22] and aryl derivatives. The reaction of aromatic compounds with allenes, known as hydroarylation reaction, consists in adding an aryl moiety to a C-C double bond, and constitutes a powerful tool to form a $\mathrm{Csp}^{3}-\mathrm{Csp}^{2}$ bond in regio- and stereoselective manner.

The first example of hydroarylation of allenes with ArH catalyzed by a transition metal was described by the group of Panunzi with a platinum(II) catalyst. [23] Since then, a lot of different transition metals ( $\mathrm{Sc},{ }^{[24,25]}$ $\mathrm{Pd}^{[26]} \mathrm{Rh}^{\left[{ }^{[27-30]}\right.} \mathrm{Ir}^{\left[{ }^{[31]}\right.} \mathrm{Co},{ }^{[32]} \mathrm{Ru},{ }^{[33]} \mathrm{Ni},{ }^{[34]} \mathrm{Mn}^{[35,36]}$ and $\mathrm{Fe}^{[37]}$ ) have also been used to perform hydroarylation of allenes with aryl nucleophiles (Scheme 1), especially from cationic gold(I) catalysts that are well known as $\pi$-acid complexes. ${ }^{[38-43]}$ Most of these hydroarylation methods are limited to electron-rich aryl nucleophiles and afford the linear product i.e. the anti-Markovnikov product (Scheme 1, equation 1). Other groups reported hydroarylation reactions with various nucleophilic partners such as aryl boronic acids $\operatorname{ArB}(\mathrm{OH})_{2},{ }^{[44]}$ aryl boronic esters $\operatorname{ArB}(\mathrm{OR})_{2}{ }^{[45]}$ or aryl halides $\mathrm{ArX}^{[46]}$ allowing an ipso-arylation. These methods allowed the addition of a wide scope of aryl partners selectively on the central carbon of the allene, affording then either the endo- or the exo-olefinic product (Scheme 1, equation 2). These two regio- divergent pathways are providing interesting products that could be further functionalized through either the C-C double bond or the (hetero)aryl group.

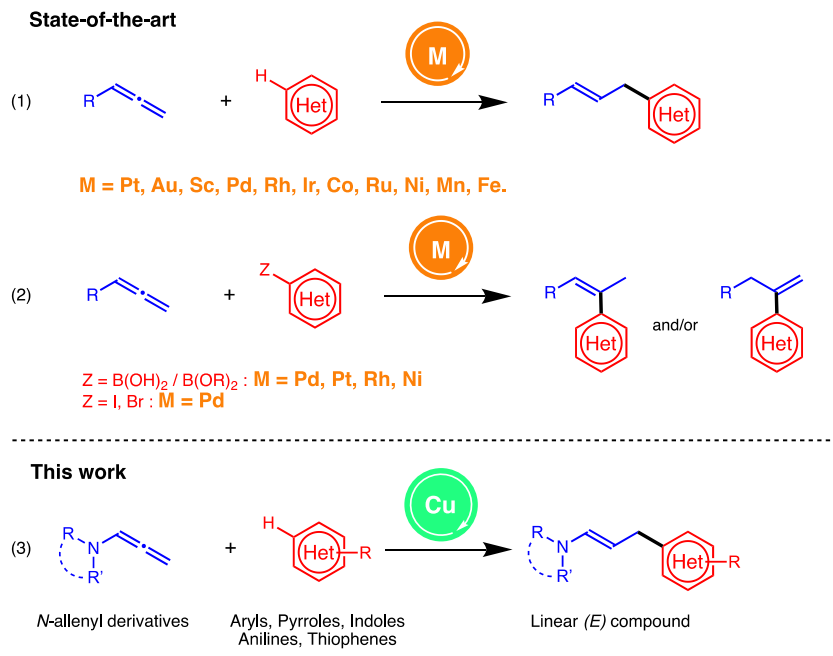

Scheme 1. Metal-catalyzed hydroarylation of allenes: known methods and pathway described herein with $\mathrm{Cu}$ catalysis

Herein, we report an unprecedented copper-catalyzed hydroarylation of allenes illustrated by the addition of aryl and heteroaryl derivatives on $N$-allenyl compounds. Based on our previous works on coppercatalyzed hydrofunctionalization of allenamides, ${ }^{[47-55]}$ we began to study the model reaction between $N$ allenyl-2-pyrrolidinone $\mathbf{1 a}$ with 1,3,5trimethoxybenzene 2a under various experimental conditions (Table 1).

Table 1. Hydroarylation of 1a with 2a: Selected data for reaction parametric study. ${ }^{\mathrm{a}}$

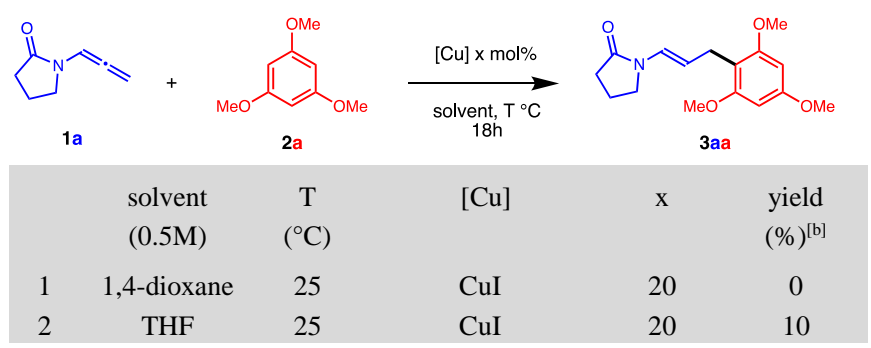




$\begin{array}{cccccc}3 & \mathrm{DMF} & 25 & \mathrm{CuI} & 20 & 17 \\ 4 & \mathrm{CH}_{3} \mathrm{CN} & 25 & \mathrm{CuI} & 20 & 23 \\ 5 & \mathrm{CH}_{3} \mathrm{CN} & 25 & - & 0 & 0 \\ 6 & \mathrm{CH}_{3} \mathrm{CN} & 25 & \mathrm{CuOAc} & 20 & 13 \\ 7 & \mathrm{CH}_{3} \mathrm{CN} & 25 & \mathrm{Cu}(\mathrm{OTf})_{2} & 20 & 16 \\ 8 & \mathrm{CH}_{3} \mathrm{CN} & 25 & \mathrm{Cu}(\mathrm{OTf})_{2} . \mathrm{PhH}_{4} & 10 & 41 \\ 9 & \mathrm{CH}_{3} \mathrm{CN} & 25 & \mathrm{Cu}\left(\mathrm{CH}_{3} \mathrm{CN}\right)_{4} \mathrm{PF}_{6} & 20 & 51 \\ 10 & \mathrm{CH}_{3} \mathrm{CN} & 80 & \mathrm{Cu}\left(\mathrm{CH}_{3} \mathrm{CN}\right)_{4} \mathrm{PF}_{6} & 20 & 76 \\ 11 & \mathrm{CH}_{3} \mathrm{CN} & 100 & \mathrm{Cu}\left(\mathrm{CH}_{3} \mathrm{CN}\right)_{4} \mathrm{PF}_{6} & 20 & 90 \\ 12 & \mathrm{CH}_{3} \mathrm{CN} & 100 & \mathrm{Cu}\left(\mathrm{CH}_{3} \mathrm{CN}\right)_{4} \mathrm{PF}_{6} & 10 & 88 \\ 13 & \mathrm{CH}_{3} \mathrm{CN} & 100 & \mathrm{Cu}\left(\mathrm{CH}_{3} \mathrm{CN}\right)_{4} \mathrm{PF}_{6} & 5 & 49 \\ 14 & \mathrm{CH}_{3} \mathrm{CN} & 100 & \mathrm{Cu}\left(\mathrm{CH}_{3} \mathrm{CN}\right)_{4} \mathrm{PF}_{6} & 10 & 57^{[\mathrm{cc}]} \\ 15 & \mathrm{CH}_{3} \mathrm{CN} & 100 & \mathrm{Cu}\left(\mathrm{CH}_{3} \mathrm{CN}\right)_{4} \mathrm{PF}_{6} & 10 & >99^{[\mathrm{d}]}\end{array}$

${ }^{\text {a }}$ Reaction conditions: 1a $(0.5 \mathrm{mmol}), \mathbf{2 a}(1.2$ equiv, $0.6 \mathrm{mmol})$ and catalyst ( 0.025 to $0.1 \mathrm{mmol})$ were placed in a screw tube under argon in $1 \mathrm{~mL}$ of solvent for $18 \mathrm{~h}$ at 25 to $100^{\circ} \mathrm{C}$. ${ }^{\mathrm{b}} \mathrm{NMR}$ yields using 4-iodoanisole as internal standard. ${ }^{\mathrm{c}}$ The mixture was reacted for 10 hours. ${ }^{\mathrm{d}}$ Reaction performed with $1 \mathrm{mmol}, 2$ equiv of $\mathbf{2 a}$.

We initially tested the reaction at $25^{\circ} \mathrm{C}$ with $20 \mathrm{~mol} \%$ of $\mathrm{CuI}$ as a catalyst in various solvents: 1,4-dioxane, THF, DMF and acetonitrile (entries 1-4, table 1). The latter was then considered as our reference solvent as it gave the desired product 3aa in $23 \%$ yield. A control experiment was conducted to prove that no reaction is occurring without any copper salts (entry 5, table 1 ). Different copper sources were then investigated, and $\mathrm{Cu}\left(\mathrm{CH}_{3} \mathrm{CN}\right)_{4} \mathrm{PF}_{6}$ allowed the best rate of formation of 3aa (entries 6-9, table 1). We observed that the higher the temperature, the better the yield up to $100^{\circ} \mathrm{C}$ (entries 9-11, table 1). We then reduced the catalyst loading, and observed at this temperature no major difference between 10 or $20 \mathrm{~mol} \%$ of $\mathrm{Cu}\left(\mathrm{CH}_{3} \mathrm{CN}\right)_{4} \mathrm{PF}_{6}$ while the yield significantly decreased with only 5 mol\% of copper (entries 12-13, table 1). Tests performed at $100{ }^{\circ} \mathrm{C}$ with $10 \mathrm{~mol} \%$ of $\mathrm{Cu}\left(\mathrm{CH}_{3} \mathrm{CN}\right)_{4} \mathrm{PF}_{6}$ showed that the reaction is not complete after 10 hours (entry 14, table 1). Finally, adding 2 equiv instead of 1.2 equiv of aryl reagent $\mathbf{2 a}$ allowed us to further increase the yield of 3aa (entry 15, table 1). The reaction was found to be totally stereo- (only the $(E)$ product was obtained) and regioselective as the addition occurred only on the terminal carbon of the allene. With these optimized conditions (entry 12 and 14 , table 1) in hand, we first explored the scope of the method for the hydroarylation of allenamide 1a with various readily available (hetero)aryl compounds $\mathbf{2 a - i}$ (Scheme 2). Noteworthy that obtained compounds are enamide-type molecules which constitute a versatile building block for medicinal chemistry and for total synthesis of natural products. ${ }^{[56]}$

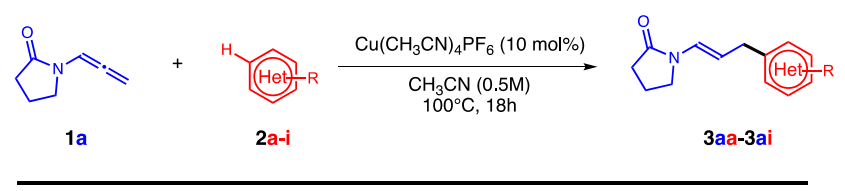

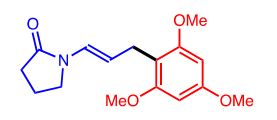

3aa $(99 \%)^{\mathrm{b}}$

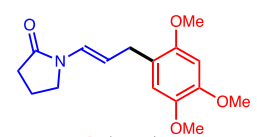

$3 a b(90 \%)$

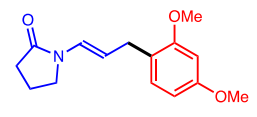

3ac $(67 \%)^{\mathrm{b}}$

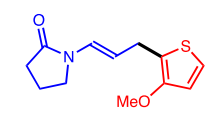

3ad $(71 \%)$

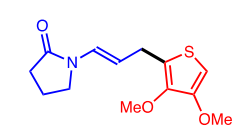

3ae (88\%) a Reaction conditions: 1a $(0.5 \mathrm{mmol}), \mathbf{2 a - i}(1.2$ equiv, $0.6 \mathrm{mmol}$, unless otherwise notified), $\mathrm{Cu}\left(\mathrm{CH}_{3} \mathrm{CN}\right)_{4} \mathrm{PF}_{6} \quad(10 \mathrm{~mol} \%$, $0.05 \mathrm{mmol}), \mathrm{CH}_{3} \mathrm{CN}(0.5 \mathrm{M}, 1 \mathrm{~mL})$, argon, $100^{\circ} \mathrm{C}, 18 \mathrm{~h}$. Isolated yields. ${ }^{\mathrm{b}}$ Reaction performed with 2 equiv, $1 \mathrm{mmol}$ of aryl partner 2.

Scheme 2. $\mathrm{Cu}\left(\mathrm{CH}_{3} \mathrm{CN}\right)_{4} \mathrm{PF}_{6}$-catalyzed hydroarylation of various (hetero)aryl compounds $2 \mathrm{a}-\mathbf{i}$ with allene $1 \mathrm{a}^{\mathrm{a}}$

The reaction of both 1,3,5-trimethoxybenzene $\mathbf{2 a}$ and 1,2,4-trimethoxybenzene $\mathbf{2 b}$ with $\mathbf{1 a}$ gave the formation of $\mathbf{3 a a}$ and $\mathbf{3 a b}$, respectively in quantitative $(>99 \%)$ and in $90 \%$ isolated yields. Whereas 1,3dimethoxybenzene 2c afforded 3ac with a lower yield of $67 \%, 1,4$-dimethoxybenzene and anisole did not yield the desired product. Different types of $\mathrm{N}$ (pyrrole, indole) or S-containing (thiophenes) heteroaromatic compounds were also successfully engaged in the reaction with 1a, affording products 3ad to 3ag in medium to excellent yields. Other heteroaromatic substrates did not provided any product under these conditions, such as substituted pyridines, toluene and 1,3,5-trimethylbenzene. The meta-substituted $N, N$-dimethylanilines $\mathbf{2 h}$ and $\mathbf{2 i}$ afforded the corresponding products 3ah and 3ai in moderate yields. It is interesting to notice that 3ah could be potentially involved in further cross-coupling reaction through its aryl bromide moiety. Noteworthy that analysis of ${ }^{1} \mathrm{H}$ NMR spectra clearly showed the exclusive formation of one product with the $(E)$ configuration of the double bond (see supporting information).
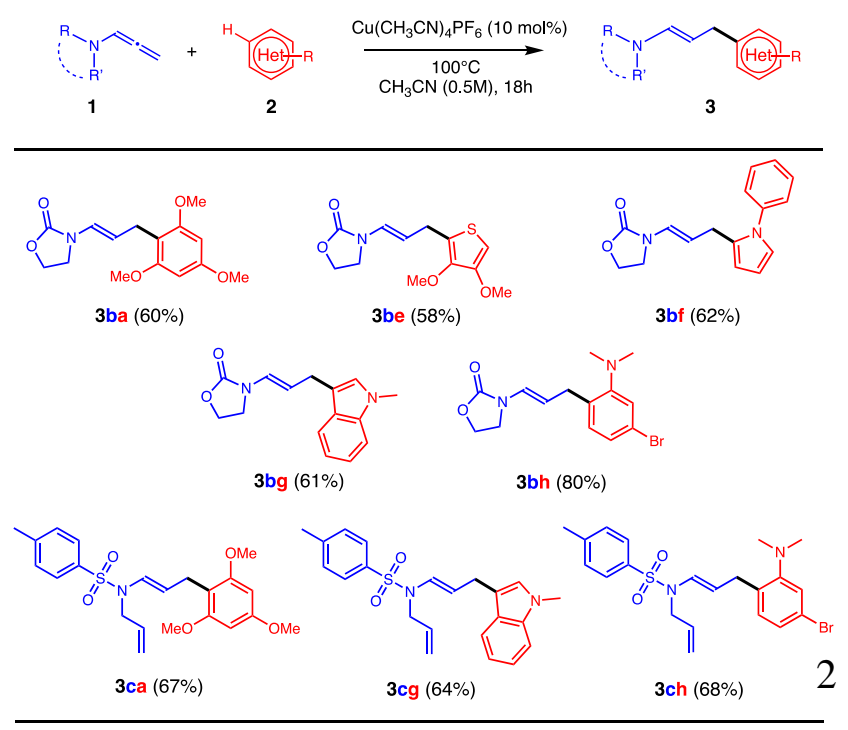
Scheme 4. Plausible mechanism for the copper-catalyzed hydroarylation of $N$-allenyl derivatives.

a Reaction conditions: 1 (0.5 mmol), 2 (2 equiv, $1 \mathrm{mmol})$, $\mathrm{Cu}\left(\mathrm{CH}_{3} \mathrm{CN}\right)_{4} \mathrm{PF}_{6}(10 \mathrm{~mol} \%, 0.05 \mathrm{mmol}), \mathrm{CH}_{3} \mathrm{CN}(0.5 \mathrm{M}, 1 \mathrm{~mL})$, argon, $100^{\circ} \mathrm{C}, 18 \mathrm{~h}$. Isolated yields.

Scheme 3. Extension to other $N$-allenyl derivatives and cross reactivity. ${ }^{\text {a }}$

Other $N$-allenyl derivatives bearing either a carbamate 1b or a sulfonamide moiety 1c were then successfully engaged in this copper-catalyzed hydroarylation, affording the corresponding products in good to high yields (Scheme 3 ). These substrates $\mathbf{1 b}$ and $\mathbf{1 c}$ afforded the corresponding linear $(E)$ products with electronrich arene (3ba, 3ca), thiophene derivatives (3be), $N$ phenyl pyrrole (3bf), indole derivatives $(\mathbf{3 b g}, \mathbf{3 c g})$ and aniline derivatives $(\mathbf{3 b h}, \mathbf{3} \mathbf{c h})$ in moderate to good yields with a total control of regio- and stereoselectivity.

Based on our previous studies ${ }^{[49,51]}$ and mechanisms described in the literature, ${ }^{[38,43,57]}$ we suggest as the first step of the process the coordination of the copper to the $\mathrm{N}$-allenyl derivative through the assisting group and the central carbon of the allene. We assume that the electron rich aryl is then reacting as a nucleophile on the terminal position of the allene. This electrophilic aromatic substitution $\left(\mathrm{S}_{\mathrm{E}} \mathrm{Ar}\right)$ leads to the formation of a plausible Wheland intermediate, which undergoes into protodecupration to afford selectively the $(E)$-product. The need of electron donating groups in adequate positions on the (hetero)aryl substrate is consistent with this mechanism proposal (Scheme 4).

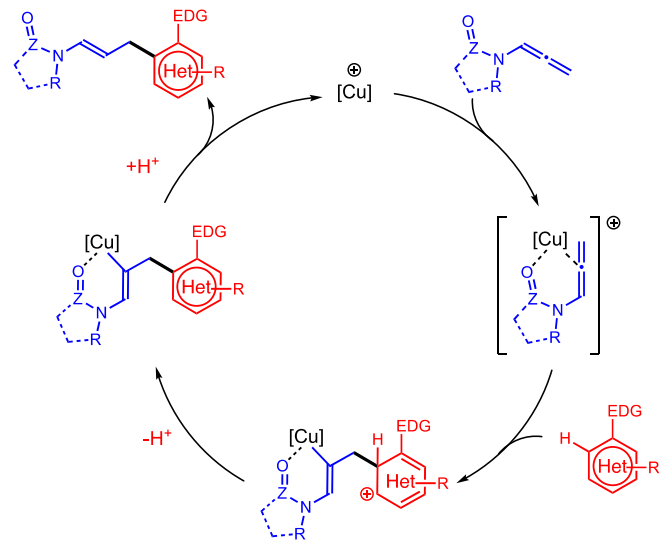

In summary, we reported an unprecedented coppercatalyzed hydroarylation of allenes illustrated by the addition of (hetero)aryl nucleophiles on $N$-allenyl derivatives which afford selectively (E)-allylic compounds with medium to excellent yields in a total atom economical fashion. Various readily available aromatic compounds were successfully engaged in the reaction with allene substrates, showing the good tolerance of the methodology. Nevertheless, we noticed that electron-rich substrates are required for the reaction to proceed, which is consistent with the literature and $\mathrm{S}_{\mathrm{E}}$ Ar-type mechanism. Further investigations on the potential of copper-catalyzed systems for hydrofunctionalization of allenes will be reported in due course.

\section{Experimental Section}

Detailed experimental procedures and characterization data for all new compounds are provided (PDF).

General procedure for hydroarylation of $N$-allenyl derivatives: An oven-dried Schlenk flask of appropriate size equipped with a magnetic stirring bar is placed under vacuum then back-filled with argon. This procedure is repeated three times. Under a stream of argon, Tetrakis(acetonitrile)copper(I) hexafluorophosphate $\mathrm{Cu}\left(\mathrm{CH}_{3} \mathrm{CN}\right)_{4} \mathrm{PF}_{6}(10 \mathrm{~mol} \%)$ is added, followed by the (hetero)aryl nucleophile (1.2 equiv or 2 equiv as mentionned in main text), acetonitrile $(0.5 \mathrm{M}, 1 \mathrm{~mL})$ and the allene $(0.5$ mmol, 1 equiv). The Schlenk flask is then sealed under a positive pressure of argon, stirred and heated at $100^{\circ} \mathrm{C}$ for 18h. After allowing the reaction to cool down to room temperature, either 1,3,5-trimethoxybenzene ( 0.33 equiv, $0.165 \mathrm{mmol}, 27.8 \mathrm{mg}$ ) or 4 -iodoanisole ( 0.33 equiv, 0.165 $\mathrm{mmol}, 38.6 \mathrm{mg}$ ) is added as internal standard. The reaction mixture is then diluted in $c a .3 \mathrm{~mL}$ of dichloromethane and extracted with water. The organic layer is dried over anhydrous magnesium sulfate $\mathrm{MgSO}_{4}$ and the solvent is removed under vacuum. The residue is then purified by triethylamine $\mathrm{NEt}_{3}$ treated silica gel column chromatography.

\section{Acknowledgements}

Financial support provided by École Nationale Supérieure de Chimie de Montpellier (ENSCM, PhD fellowship for RA and LP), Institut Universitaire de France (IUF, FM) and Centre National de la Recherche Scientifique (CNRS) are warmly acknowledged with thanks.

\section{References}


[1] S. Ma, Chem. Rev. 2005, 105, 2829-2871.

[2] M. P. Muñoz, Chem. Soc. Rev. 2014, 43, 3164 3183.

[3] J. M. Alonso, M. T. Quirós, M. P. Muñoz, Org. Chem. Front. 2016, 3, 1186-1204.

[4] P. Koschker, B. Breit, Acc. Chem. Res. 2016, 49, 1524-1536.

[5] R. Zimmer, C. U. Dinesh, E. Nandanan, F. A. Khan, Chem. Rev. 2000, 100, 3067-3125.

[6] M. P. Muñoz, Org. Biomol. Chem. 2012, 10, 3584-3594.

[7] J. Le Bras, J. Muzart, Chem. Soc. Rev. 2014, 43, 3003-3040.

[8] G. Li, X. Huo, X. Jiang, W. Zhang, Chem. Soc. Rev. 2020, 49, 2060-2118.

[9] L. J. Hilpert, B. Breit, Angew. Chem. Int. Ed. 2019, 58, 9939-9943.

[10] R. Blieck, R. Abed Ali Abdine, M. Taillefer, F. Monnier, Org. Lett. 2018, 20, 2232-2235.

[11] H. Zhou, Y. Wang, L. Zhang, M. Cai, S. Luo, J. Am. Chem. Soc. 2017, 139, 3631-3634.

[12] B. M. Trost, A. B. C. Simas, B. Plietker, C. Jäkel, J. Xie, Chem. Eur. J. 2005, 11, 7075-7082.

[13] S. Arai, Y. Amako, X. Yang, A. Nishida, Angew. Chem. Int. Ed. 2013, 52, 8147-8150.

[14] H. Hori, S. Arai, A. Nishida, Adv. Synth. Catal. 2017, 359, 1170-1176.

[15] K. Matsumoto, S. Arai, A. Nishida, Tetrahedron 2018, 74, 2865-2870.

[16] J. Long, J. Gao, X. Fang, Org. Lett. 2020, 22, 376380 .

[17] B. M. Trost, G. Kottirsch, J. Am. Chem. Soc. 1990 , 112, 2816-2818.

[18] C. P. Grugel, B. Breit, Org. Lett. 2018, 20, 10661069.

[19] L. Jeanne-Julien, G. Masson, R. Kouoi, A. Regazzetti, G. Genta-Jouve, V. Gandon, E. Roulland, Org. Lett. 2019, 21, 3136-3141.

[20] W. Li, N. Chen, J. Montgomery, Angew. Chem. Int. Ed. 2010, 49, 8712-8716.

[21] S. Parisotto, L. Palagi, C. Prandi, A. Deagostino, Chem. Eur. J. 2018, 24, 5484-5488.

[22] G. Xu, B. Fu, H. Zhao, Y. Li, G. Zhang, Y. Wang, T. Xiong, Q. Zhang, Chem. Sci. 2019, 10, 18021806.

[23] D. Renzi, A. Panunzi, A. Saporito, A. Vitagliano, J. Chem. Soc. Perkin Trans 1983, 2, 993-996.

[24] S. Ma, S. Yu, Org. Lett. 2005, 7, 5063-5065.

[25] G. Song, B. Wang, M. Nishiura, Z. Hou, Chem. Eur. J. 2015, 21, 8394-8398.
[26] Z. Fang, C. Fu, S. Ma, Chem. Eur. J. 2010, 16, 3910-3913.

[27] R. Zeng, C. Fu, S. Ma, J. Am. Chem. Soc. 2012, 134, 9597-9600.

[28] B. Ye, N. Cramer, J. Am. Chem. Soc. 2013, 135, 636-639.

[29] Z.-J. Jia, C. Merten, R. Gontla, C. G. Daniliuc, A. P. Antonchick, H. Waldmann, Angew. Chem. Int. Ed. 2017, 129, 2469-2474.

[30] C. Ghosh, P. J. Nagtilak, M. Kapur, Org. Lett. 2019, 21, 3237-3241.

[31] Y. J. Zhang, E. Skucas, M. J. Krische, Org. Lett. 2009, 11, 4248-4250.

[32] S. Nakanowatari, R. Mei, M. Feldt, L. Ackermann, ACS Catal. 2017, 7, 2511-2515.

[33] S. Nakanowatari, L. Ackermann, Chem. Eur. J. 2015, 21, 16246-16251.

[34] S. Nakanowatari, T. Müller, J. C. A. Oliveira, L. Ackermann, Angew. Chem. Int. Ed. 2017, 56, 15891-15895.

[35] C. Wang, A. Wang, M. Rueping, Angew. Chem. Int. Ed. 2017, 129, 10067-10070.

[36] S. Y. Chen, Q. Li, H. Wang, J. Org. Chem. 2017, 82, 11173-11181.

[37] A. M. Messinis, L. H. Finger, L. Hu, L. Ackermann, J. Am. Chem. Soc. n.d., O, null.

[38] R. Skouta, C. J. Li, Can. J. Chem. 2008, 86, 616620.

[39] K. L. Toups, G. T. Liu, R. A. Widenhoefer, J. Organomet. Chem. 2009, 694, 571-575.

[40] C. N. Kona, M. H. Shinde, C. V Ramana, Org. Biomol. Chem. 2015, 13, 5358-5362.

[41] M. Z. Wang, C. Y. Zhou, Z. Guo, E. L. M. Wong, M. K. Wong, C. M. Che, Chem. Asian J. 2011, 6, 812-824.

[42] D. R. Sutherland, L. Kinsman, S. M. Angiolini, G. M. Rosair, A. L. Lee, Chem. Eur. J. 2018, 24, 7002-7009.

[43] M. C. Kimber, Org. Lett. 2010, 12, 1128-1131.

[44] S. Ma, N. Jiao, L. Ye, Chem. Eur. J. 2003, 9 , 6049-6056.

[45] G. Takahashi, E. Shirakawa, T. Tsuchimoto, Y. Kawakami, Adv. Synth. Catal. 2006, 348, 837-840.

[46] I. Shimizu, T. Sugiura, J. Tsuji, J. Org. Chem. 1985, 50, 537-539.

[47] R. Blieck, R. Abed Ali Abdine, M. Taillefer, F. Monnier, Org. Lett. 2018, 20, 2232-2235.

[48] R. Blieck, S. Lemouzy, M. Taillefer, F. Monnier, 2020, DOI 10.26434/chemrxiv.11830935.v3.

[49] L. A. Perego, R. Blieck, A. Groué, F. Monnier, M. 
Taillefer, I. Ciofini, L. Grimaud, ACS Catal. 2017, 7, 4253-4264.

[50] R. Blieck, J. Bahri, M. Taillefer, F. Monnier, Org. Lett. 2016, 18, 1482-1485.

[51] L. A. Perego, R. Blieck, J. Michel, I. Ciofini, L. Grimaud, M. Taillefer, F. Monnier, Adv. Synth. Catal. 2017, 359, 4388-4392.

[52] R. Blieck, L. Perego, I. Ciofini, L. Grimaud, M. Taillefer, F. Monnier, Synthesis 2019, 51, 12251234.

[53] R. Blieck, R. Abed Ali Abdine, M. Taillefer, F. Monnier, Org. Lett. 2018, 20, 2232-2235.

[54] R. Blieck, M. Taillefer, F. Monnier, J. Org. Chem. 2019, 84, 11247-11252.

[55] A. N. Philippova, D. V Vorobyeva, F. Monnier, S. N. Osipov, Org. Biomol. Chem. 2020, 18, 32743280 .
[56] T. Courant, G. Dagousset, G. Masson, Synthesis 2015, 47, 1799-1826.

[57] K. L. Toups, G. T. Liu, R. A. Widenhoefer, J. Organomet. Chem. 2009, 694, 571-575. 


\section{FULL PAPER}

\section{Hydroarylation of $N$-Allenyl Derivatives} Catalyzed by Copper

The regio- and stereoselective addition of (hetero)aryl nucleophiles to $N$-allenyl derivatives is described under copper catalysis. represents the first example of hydroarylation of allenes catalyzed by copper.

\section{KEYTOPIC: Allene hydroarylation}

Racha Abed Ali Abdine, Lucas Pagès, Marc

Taillefer, ${ }^{*}$ and Florian Monnier*

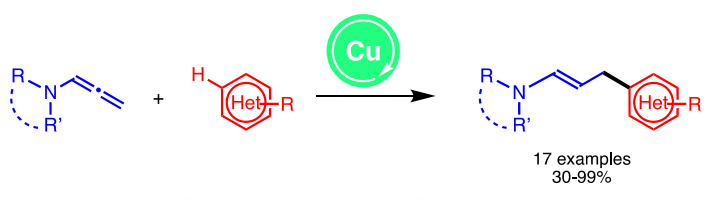

$\checkmark$ Regioselective $\nabla$ Stereoselective $\nabla 100 \%$ atom-economical 